Check for updates

Cite this: RSC Adv., 2018, 8, 30678

Received 18th May 2018

Accepted 16th August 2018

DOI: $10.1039 / \mathrm{c} 8 \mathrm{ra04249g}$

rsc.li/rsc-advances

\title{
Synthesis and investigation of new cyclic molecules using the stilbene scaffold $\dagger$
}

\author{
Piotr Tobiasz, Marcin Poterała, Eliza Jaśkowska and Hanna Krawczyk (DD *
}

\begin{abstract}
A new approach to the synthesis of asymmetrical cyclic compounds using a stilbene scaffold has been developed. The use of boron trifluoride diethyl etherate as the catalyst, both with and without paraformaldehyde, allows us to obtain new substituted dioxanes, oxanes, cyclic compounds or dimer. The analysis of products was run using experimental and theoretical methods.
\end{abstract}

Various macrocycles have been widely investigated due to their interesting conformational characteristics and abundant hostguest properties. New macrocyclic receptors with high selectivity in molecular recognition are being looked for, ${ }^{\mathbf{1}}$ because they have many possible applications in the construction of diverse supramolecular systems. ${ }^{2-15}$ In particular, various drugdelivery systems for tumours are being tested and looked at. Development of most solid tumours is strictly associated with the formation of their own functional vascular supply, the network of which is typically obtained in the process of angiogenesis from the host's normal vascular system. The particular occurrence of tumour neo-vasculature is regarded as a wellfitting target for cancer cell annihilation. Two forms of vascular targeting agents (VTAs) can be distinguished. The first category concerns the substances that inhibit the angiogenesis process (they are referred to as the angiogenesis inhibitors, AIs). The second variant (referred to as the vascular disrupting agents, VDAs), ${ }^{16}$ are the compounds harmful to the alreadyestablished vessels. Combretastatins CA1P (OXi4503) and CA4P (a subtype of natural phenols) are new vascular disrupting and vascular targeting agents. ${ }^{16}$ They exhibit significant abilities of gastric tumour metastasis inhibition and of antitumor immune reactivity enhancement. ${ }^{17}$ These compounds additionally contain a notable characteristic of differentiated methoxy groups in the framework. Continuing our study concerning the synthesis and searching the biological activity of stilbenes ${ }^{18}$ and drug-delivery systems for tumours, we directed our attention to the new substituted dioxanes, oxanes, and cyclic compounds. We conducted studies on the reaction of substituted stilbenes and paraformaldehyde in the presence of a Lewis acid as the catalyst $\left(\mathrm{BF}_{3} \cdot \mathrm{OEt}_{2}\right)$ (Table 1 and 2$)$. The acidcatalyzed condensation of olefins with aldehydes, the Prins reaction, is generally used for the preparation of 1,3-dioxanes. ${ }^{19}$

Department of Organic Chemistry, Faculty of Chemistry, Warsaw University of Technology, Noakowskiego 3, 00-664 Warsaw, Poland. E-mail: hkraw@ch.pw.edu.pl $\dagger$ Electronic supplementary information (ESI) available: Experimental procedures, spectroscopic characterization of all new compounds, the optimum ground-state geometry for compounds $(\mathbf{1 2}, \mathbf{1 3}, \mathbf{1 5}, \mathbf{1 6})$. See DOI: $10.1039 / \mathrm{c} 8 \mathrm{ra04249g}$
The major products of the classical Prins reaction are normally 1,3-dioxanes, 1,3-glycols, or unsaturated alcohols depending on the reaction conditions ${ }^{\mathbf{1 9}}$ (Fig. 1). The aza-Prins cyclization, which is the nitrogen version of the reaction, is of particular interest. The reaction permits rapid access to azaheterocycles and the wide applicability and usefulness of the aza-Prins reaction have been demonstrated by the synthesis of a variety of complex natural products. ${ }^{20}$

It is known that catalyst influence stereocontrol of Prins cyclization. For example, in Prins cyclization various aldehydes and dienyl alcohols catalyzed by a confined chiral imidodiphosphoric acid (IDP), the 2,3-disubstituted tetrahydrofurans, are obtained products with excellent diastereo- and enantioselectivities. ${ }^{20 e}$ In the case of rhenium(VII) complex, an effective catalyst for Prins cyclizations using aromatic and $\alpha$ and $\beta$-unsaturated aldehydes, the substituted 4-hydroxytetrahydropyran products are formed stereoselectively. ${ }^{\mathbf{2 0 d}}$ Therefore, we assumed that the reaction with the stilbenes would also be stereoselective. The reaction of bromostilbene (1), 4-bromo- $4^{\prime}$ -

Table 1 The compounds of (7-10) obtained from the reaction of suitable stilbene derivatives (1-4) with paraformaldehyde and $\mathrm{BF}_{3}$ - $\mathrm{OEt}_{2}$ as the catalyst ${ }^{a}$

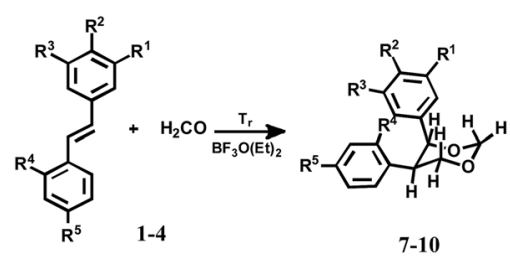

\begin{tabular}{lllllll}
\hline Entry & $\mathrm{R}^{1}$ & $\mathrm{R}^{2}$ & $\mathrm{R}^{3}$ & $\mathrm{R}^{4}$ & $\mathrm{R}^{5}$ & Yield (\%) \\
\hline $1 / 7$ & $\mathrm{H}$ & $\mathrm{Br}$ & $\mathrm{H}$ & $\mathrm{H}$ & $\mathrm{H}$ & 25 \\
$2 / 8$ & $\mathrm{H}$ & $\mathrm{Br}$ & $\mathrm{H}$ & $\mathrm{H}$ & $\mathrm{NO}_{2}$ & 20 \\
$3 / 9$ & $\mathrm{OCH}_{3}$ & $\mathrm{H}$ & $\mathrm{OCH}_{3}$ & $\mathrm{NO}_{2}$ & $\mathrm{NO}_{2}$ & $\mathrm{~A}$ little \\
$4 / 10$ & $\mathrm{H}$ & $\mathrm{OCH}_{3}$ & $\mathrm{H}$ & $\mathrm{H}$ & $\mathrm{Br}$ & 25
\end{tabular}

${ }^{a}$ Tr-room temperature, stoichiometry of substates $1 \mathrm{mmol}: 1 \mathrm{mmol}$, $\mathrm{BF}_{3} \cdot \mathrm{OEt}_{2}-2 \mathrm{mmol}$, time reaction- $3 \mathrm{~h}$ (above $3 \mathrm{~h}$ increased the yield of the polymeric product). 
nitrostilbene (2) and 3,5-dimethoxy-2' $4^{\prime}$-dinitrostilbene (3) with paraformaldehyde occurs according to the Prins mechanism and are obtained 1,3-dioxanes (7-9) (Table 1). The reaction time significantly affects the product yields. It was found that the best reaction time was 1.5-2 hours and that further extending the time decreased the yields (polymeric product). Serendipitously, substituent in stilbene scaffold influences the course of this reaction. When 4 -bromo- $4^{\prime}$-methoxystilbene (4) reacts, the 1,3 -dioxane (10) is only observed with $25 \%$ yield. In this reaction, the main product, oxane (11) is obtained with $60 \%$ yield (Table 2). In turn, when symmetrically substituted stilbene (5) or stilbene (6) were used in the reaction, asymmetrical cyclic molecules $(\mathbf{1 2}, \mathbf{1 3})$ were obtained (Table 2). In order to determine the structure of reaction products in solution, ${ }^{1} \mathrm{H}$ and ${ }^{13} \mathrm{C}$ spectra of all the products were measured (in $\mathrm{CDCl}_{3}$, complete data are shown in ESI $\dagger$ ). ${ }^{13} \mathrm{C}$ NMR resonances were assigned unequivocally, based on the combined information from 1D to 2D NMR (gCOSY, gHSQC and gHMBC) experiments. Coupling constants $\left({ }^{1} \mathrm{H}^{-1} \mathrm{H}\right)$ were measured directly from resolutionenhanced 1D spectra and confirmed, when necessary, by homo-decoupling. gHSQC and gHMBC analysis allowed the assignment of the compounds regiochemistry. The stereochemistry of the obtained products was determined by coupling constants from ${ }^{1} \mathrm{H}$ NMR spectra (see ESI $\dagger$ ). All coupling constants in $(7,8,10)$ for protons $\mathrm{H} 4-\mathrm{H} 5, \mathrm{H} 5-\mathrm{H} 6$ are about $10 \mathrm{~Hz}$ (axial-axial position, a-a), because the benzene rings are predominantly in the equatorial position. In the case of the product (11), the coupling constants for protons $\mathrm{H} 2-\mathrm{H} 3$ and $\mathrm{H} 3-\mathrm{H} 4$ are about $10 \mathrm{~Hz}$ (protons in a-a position and benzene rings in equatorial position) but the coupling constants for protons $\mathrm{H} 4-\mathrm{H} 5$ are about $4 \mathrm{~Hz}$. This shows that the remaining $\mathrm{H} 5$ proton is predominantly in the equatorial position in relation to the H4. For compounds $(\mathbf{1 2}, \mathbf{1 3})$ the coupling constants for protons $\mathrm{H} 1-\mathrm{H} 2, \mathrm{H} 2-\mathrm{H} 3$ and $\mathrm{H} 3-\mathrm{H} 4$ are about $10-11 \mathrm{~Hz}$ (the coupling for $\mathrm{H} 3-\mathrm{H} 4^{\prime}$ is about $4 \mathrm{~Hz}$ ). This shows that all the rings are predominantly in equatorial position in relation to the previous one. The stereochemistry of products depends on the reaction mechanism. In all instances, substrates (1-4) were converted to 1,3-dioxanes (7-10) in the Prins reactions (Fig. 2).

Table 2 The compound of (11) obtained from reaction of (4) with $\mathrm{BF}_{3} \cdot \mathrm{OEt}_{2}$ as the catalyst and paraformaldehyde. Products (12 and 13) were achieved also without paraformaldehyde

\begin{tabular}{llllllll}
\hline Entry & $\mathrm{R}^{1}$ & $\mathrm{R}^{2}$ & $\mathrm{R}^{3}$ & $\mathrm{R}^{4}$ & $\mathrm{R}^{5}$ & $\mathrm{R}^{6}$ & Yield (\%) \\
\hline $4 / 11$ & $\mathrm{H}$ & $\mathrm{OCH}_{3}$ & $\mathrm{H}$ & $\mathrm{H}$ & $\mathrm{Br}$ & $\mathrm{H}$ & 60 \\
$5 / 12$ & $\mathrm{H}$ & $\mathrm{OCH}_{3}$ & $\mathrm{H}$ & $\mathrm{H}$ & $\mathrm{OCH}_{3}$ & $\mathrm{H}$ & 70 \\
$6 / 13$ & $\mathrm{OCH}_{3}$ & $\mathrm{OCH}_{3}$ & $\mathrm{OCH}_{3}$ & $\mathrm{H}$ & $\mathrm{Br}$ & $\mathrm{H}$ & 80
\end{tabular}

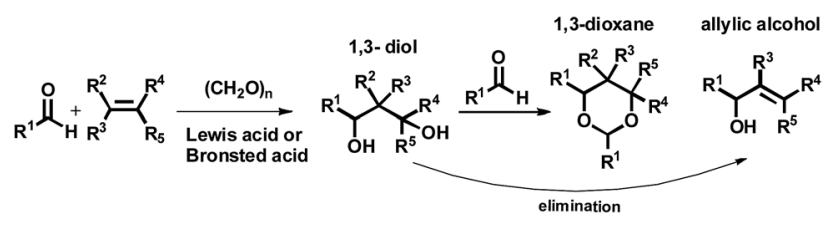

Fig. 1 Prins reaction.
Accordingly, the stilbene is attacked by an activated formaldehyde species (complex $\mathrm{H}_{2} \mathrm{CO} \cdot \mathrm{BF}_{3} \cdot \mathrm{OEt}_{2}$ ) in the first step of the reaction. Since a cyclization to a four-membered oxetane is disfavoured, the second formaldehyde molecule is connected, leading to 1,3-dioxane. The cyclization precursor (for substrates 1-4) is presumably the chiral carbenium ion I. The two faces of the carbenium ion are diastereotopic due to the communicating stereogenic center. A differentiation results from the difference in size of the hydrogen atom and the phenyl moiety. The hydrogen atom assumes the pseudoaxial position in the transition state of cyclization, as is presented in Fig. 2. The supposition of the carbenium ion intermediate is consistent with the observed stereoconvergency of the reaction for the 1-phenylpropen-1-en. ${ }^{20}$ Another main product was obtained with 4bromo-4'-methoxystilbene (11) in addition to Prins (10).

The compound (11) is built with two scaffolds of 4-bromo- $4^{\prime}$ methoxystilbene and one molecule of formaldehyde. It can be observed that the regiochemistry and stereochemistry for the one molecule of stilbene are the same for (11) and (10). It is worth noting that due to the steric bulk of Lewis acid (2,6-di-tertbutylphenoxy)difluoroborane, a potential electrophilic complex $\mathrm{H}_{2} \mathrm{CO} \cdot \mathrm{BF}_{2} \cdot \mathrm{OAr}$ (Bach and Löbel ${ }^{21}$ ) is sensitive towards the substitution patterns in $\beta$-substituted styrenes. Whereas 1phenylprop-1-ene showed reactivity, other bulk styrenes did not react at all. The catalyst $\mathrm{BF}_{3} \cdot \mathrm{OEt}_{2}$ is not so steric-limited and probably in Prins reaction product (10) is obtained. The stereochemistry of the obtained products was determined by coupling constants from ${ }^{1} \mathrm{H}$ NMR spectra. The course of reaction toward product (10) relates to the mesomeric effect of the methoxy group, which stabilizes the positive charge on carbon atom $\alpha$ compared to the rest of the molecule. The mechanism of reaction for product (11) is unknown. Presumably, the product is obtained from carbenium ion II (Fig. 3). It is formed from one molecule of formaldehyde, one molecule of stilbene derivative and $\mathrm{BF}_{3} \cdot \mathrm{OEt}_{2}$. This intermediate reacts with the next polarizable molecule of substituted stilbene. The hypothesis of II carbenium ion intermediate is compliant with the regiochemical course of reaction toward product (11). As it was already mentioned, the stereochemistry for the first molecule of stilbene is the same for (11) and (10) (protons $\mathrm{H} 2-\mathrm{H} 3$ and $\mathrm{H} 3-\mathrm{H} 4$ are in the axial-axial position, and the $\mathrm{H} 5$ proton is in the equatorial position). Probably, the arrangement of the second stilbene molecule depends on hindrances in the forming

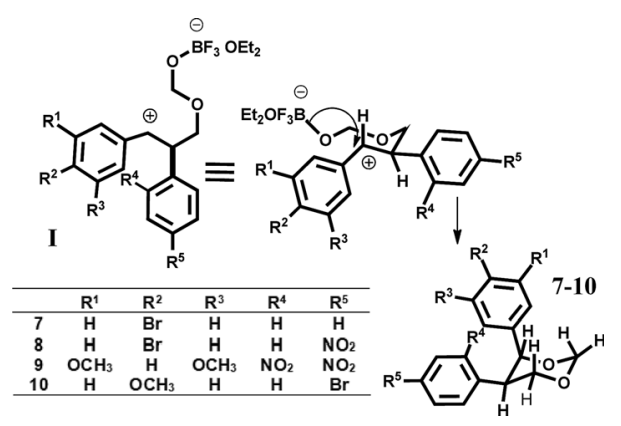

Fig. 2 Putative intermediate I en route to the formation compounds 1,3-dioxanes (7-10). 


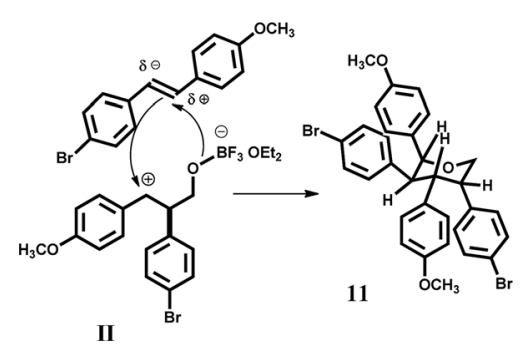

Fig. 3 Putative intermediate II en route to the formation compound (11).

product. In turn, asymmetrical cyclic products $(12,13)$ are created from symmetrical (5) and asymmetrical (6) substrates.

In this case, two stilbene molecules react with each other in the presence of Lewis acid as a catalyst and with paraformaldehyde (Fig. 4).

When the reactions were carried out without paraformaldehyde products (12) and (13) were obtained. We concluded that the addition of these compounds did not affect the course of the reaction. Moreover, the product is not observed when there is no catalyst in the reaction. The substrates (5) or (6) react with the aromatic ring of the second stilbene in Diels-Alder cyclization (the diene moiety is activated by methoxy group, and the dienophile is catalyzed by the Lewis $\mathrm{BF}_{3} \cdot \mathrm{OEt}_{2}$ acid). After the Diels-Alder reaction, the proton movement leads to the tetralin (12) and (13). Note that the presented syntheses allow the preparation of a wide range of polycyclic aromatic arenes as well as heteroarene structures. After optimization of the reaction conditions in the presence of $\mathrm{BF}_{3} \cdot \mathrm{OEt}_{2}$ with respect to the reaction solvent, temperature, and catalyst amount, the cyclic compounds (12) and (13) were prepared in $90 \%$ and $85 \%$ yields, respectively. According to the method presented in ref. 22, where iodine was found to be an effective reagent for cross-coupling of olefins with aldehydes to produce 1,3-dioxane derivative, we examined this reaction with paraformaldehyde and (1-6). It is notable that only for substrate (5) the reaction proceeded and product (12) was obtained. Product (12), similarly to the reaction with $\mathrm{BF}_{3} \cdot \mathrm{OEt}_{2}$, was created independently of the paraformaldehyde presence (yield $70 \%$ with paraformaldehyde or $90 \%$ without it). We concluded that $\mathrm{BF}_{3} \cdot \mathrm{OEt}_{2}$ was a more effective reagent than iodine in the presented reactions. Because of the chemical activity of the olefin bond of 1,2-diphenylethylene, stilbene is not a suitable starting compound for synthesis of stilbene derivatives, which is why we explored dibenzo $[b, f]$ oxepin
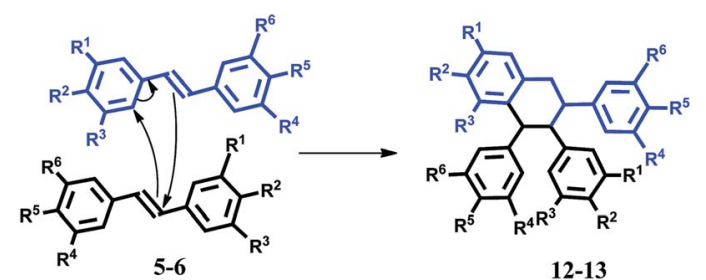

Fig. 4 Suggested mechanism of creation of the cyclic stilbenes (12) and (13).

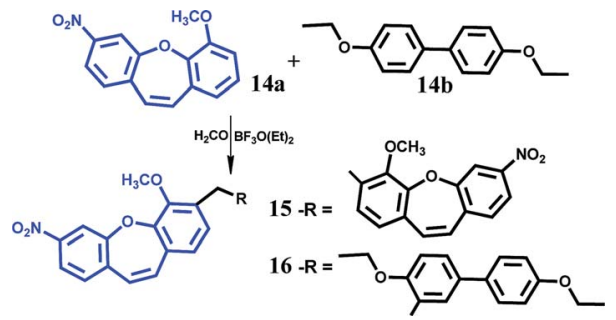

Fig. 5 The formation of dimer (15) and product (16).

(14a). Moreover, this structure is an important scaffold in medicinal chemistry and molecules with this skeleton exhibit medicinal and drug properties. ${ }^{16-18}$ With this aim in mind, we used in the synthesis methoxy dibenzo[ $[b, f]$ oxepin and obtained dimer (15) (100\% yield), in which the olefin bond was not reacting and the scaffold of $Z$-stilbene was preserved (Fig. 5). In order to expand the scope of this reaction, we examined the reaction of (14a) with (14b) (Fig. 5).

This process was successfully conducted, which enables the incorporation of aryl groups (product 16, 60\% yield) to the dibenzo $[b, f]$ oxepin framework. Considering that the combination of experimental and computational work should allow a complete characterization of the compounds and in order to explain the selectivity of cyclization, we calculated energy minima of the reactants in solution and NMR parameters (see ESI $\dagger$ ). The optimum structure of 12, 13, 15, 16 using the DFT B3LYP/6-31G* method was calculated. The influence of the solvent was described using the polarizable continuum model (PCM). Proton and ${ }^{13} \mathrm{C}$ carbon chemical shifts were calculated using GIAO-DFT method. The conclusions coming from comparison of the experimental and theoretical spectra have supported the adopted signal assignments and confirmed the structure.

In summary, we have developed a new easy synthesis of asymmetrical cyclic compounds derivatives of tetralin with high yield. What is notable, when the asymmetrically substituted (also with different groups) stilbenes reacted, dioxanes and oxanes were created respectively. Our study has provided a very concise method of constructing the derivative dibenzo $[b, f]$ oxepin framework. Such structures can be easily transformed into branched stilbene molecules. Furthermore, products (12), (13), (15) and (16) are interesting building blocks for synthesis and the biological activity of the obtained molecules will be investigated and tested for/as nanoplatforms system drug-delivery systems for tumours. ${ }^{23}$

\section{Conflicts of interest}

There are no conflicts to declare.

\section{Acknowledgements}

All authors have given approval to the final version of the manuscript. This work was supported by Faculty of Chemistry Warsaw University of Technology. 


\section{Notes and references}

1 (a) J. Zhou, J. Yang, B. Hua, L. Shao, Z. Zhang and G. Yu, Chem. Commun., 2016, 52, 1622; (b) E. R. Kay, D. A. Leigh and F. Zerbetto, Angew. Chem., Int. Ed., 2007, 46, 72; (c) Z. Niu and H. W. Gibson, Chem. Rev., 2009, 109, 6024.

2 (a) Q. Duan, Y. Cao, Y. Li, X. Hu, T. Xiao, C. Lin, Y. Pan and L. Wang, J. Am. Chem. Soc., 2013, 135, 10542; (b) H. Zhang, X. Ma, K. T. Nguyen and Y. Zhao, ACS Nano, 2013, 7, 7853; (c) G. Yu, W. Yu, Z. Mao, C. Gao and F. Huang, Small, 2015, 11, 919.

3 (a) A. Harada, Acc. Chem. Res., 2001, 34, 456; (b) H. Li, J.-N. Zhang, W. Zhou, H. Zhang, Q. Zhang, D.-H. Qu and H. Tian, Org. Lett., 2013, 15, 3070; (c) A. C. Fahrenbach, C. J. Bruns, H. Li, A. Trabolsi, A. Coskun and J. F. Stoddart, Acc. Chem. Res., 2014, 47, 482.

4 (a) Z. Niu, F. Huang and H. W. Gibson, J. Am. Chem. Soc., 2011, 133, 2836; (b) Z. Zhang, Y. Luo, J. Chen, S. Dong, Y. Yu, Z. Ma and F. Huang, Angew. Chem., Int. Ed., 2011, 50, 1397; (c) Y.-K. Tian, Z.-S. Yang, X.-Q. Lv, R.-S. Yao and F. Wang, Chem. Commun., 2014, 50, 9477.

5 (a) M. R. Ghadiri, J. R. Granja and L. K. Buehler, Nature, 1994, 369, 301; (b) X.-B. Hu, Z. Chen, G. Tang, J.-L. Hou and Z.-T. Li, J. Am. Chem. Soc., 2012, 134, 8384.

6 (a) N. L. Strutt, R. S. Forgan, J. M. Spruell, Y. Y. Botros and J. F. Stoddart, J. Am. Chem. Soc., 2011, 133, 5668; (b) G. Yu, Z. Zhang, C. Han, M. Xue, Q. Zhou and F. Huang, Chem. Commun., 2012, 48, 2958.

7 (a) L. Chen, Y.-K. Tian, Y. Ding, Y.-J. Tian and F. W. Wang, Macromolecules, 2012, 45, 8412; (b) S. Li, G.-H. Weng, W. Lin, Z.-B. Sun, M. Zhou, B. Zhu, Y. Ye and J. Wu, Polym. Chem., 2014, 5, 3994; (c) M. Zhang, X. Yan, F. Huang, Z. Niuand and H. W. Gibson, Acc. Chem. Res., 2014, 47, 1995.

8 (a) M. Song, Z. Sun, C. Han, D. Tian, H. Li and J. S. Kim, Chem.-Asian J., 2014, 9, 2344; (b) X. Zeng, J. Ma, L. Luo, L. Yang, X. Cao, D. Tian and H. Li, Org. Lett., 2015, 17, 2976; (c) G. Nie, Y. Sun, F. Zhang, M. Song, D. Tian, L. Jiang and H. Li, Chem. Sci., 2015, 6, 5859.

9 (a) Y. Wang, N. Ma, Z. Wang and X. Zhang, Angew. Chem., Int. Ed., 2007, 46, 2823; (b) A. Harada, Y. Takashima and H. Yamaguchi, Chem. Soc. Rev., 2009, 38, 875.

10 (a) C. Han, F. Ma, Z. Zhang, B. Xia, Y. Yu and F. Huang, Org. Lett., 2010, 12, 4360; (b) D. Cao and H. Meier, Asian J. Org. Chem., 2014, 3, 244; (c) Y. Wang, J.-F. Xu, Y.-Z. Chen, L.-Y. Niu, L.-Z. Wu, C.-H. Tung and Q.-Z. Yang, Chem. Commun., 2014, 50, 7001; (d) W.-B. Hu, W.-J. Hu, Y. A. Liu, J.-S. Li, B. Jiang and K. Wen, Org. Lett., 2015, 17, 2940.

11 (a) J. W. Lee, S. Samal, N. Selvapalam, H.-J. Kimand and K. Kim, Acc. Chem. Res., 2003, 36, 621; (b) J. Lagona, P. Mukhopadhyay, S. Chakrabarti and L. Isaacs, Angew. Chem., Int. Ed., 2005, 44, 4844; (c) E. A. Appel, J. Barrio, X. J. Loh and O. A. Scherman, Chem. Soc. Rev., 2012, 41, 6195. 12 Q.-H. Guo, Z.-D. Fu, L. Zhao and M.-X. Wang, Angew. Chem., Int. Ed., 2014, 53, 13548.

13 (a) H. Chen, J. Fan, X. Hu, J. Ma, S. Wang, J. Li, Y. Yu, X. Jiaand and C. Li, Chem. Sci., 2015, 6, 197; (b) J. Zhou,
G. Yu, L. Shao, B. Hua and F. Huang, Chem. Commun., 2015, 51, 4188; (c) J. Ma, H. Deng, S. Ma, J. Li, X. Jia and C. Li, Chem. Commun., 2015, 51, 6621.

14 (a) V. Balzani, M. Gomez-Lopez and J. F. Stoddart, Acc. Chem. Res., 1998, 31, 405; (b) S. T. J. Ryan, J. Del Barrio, I. Ghosh, F. Biedermann, A. I. Lazar, Y. Lan, R. J. Coulston, W. M. Nau and O. A. Scherman, J. Am. Chem. Soc., 2014, 136, 9053.

15 (a) H. Zhou, Y. Zhao, G. Gao, S. Li, J. Lan and J. You, J. Am. Chem. Soc., 2013, 135, 14908; (b) Z. He, X. Yang and W. Jiang, Org. Lett., 2015, 17, 3880.

16 (a) R. M. Horsman, A. B. Bohn and M. Busk, Exp. Oncol., 2010, 32(3), 143; (b) S. Senan and E. F. Smit, Oncologist, $2007,12,465$.

17 (a) H. Lin, S. Chiou, C. Wu, et al., J. Pharmacol. Exp. Ther., 2007, 323, 365; (b) J. Cummings, M. Zweifel, N. Smith, P. Ross, J. Peters, G. Rustin, P. Price, M. R. Middleton, T. Ward and C. Dive, Br. J. Cancer, 2012, 106(11), 1766; (c) H. W. Salmon and D. W. Siemann, Clin. Cancer Res., 2006, 12, 4090.

18 (a) J. Jakubowska, J. Mikuła-Pietrasik, K. Książek and H. Krawczyk, BioMed Res. Int., 2014, 2014, 320895, DOI: 10.1155/2014/320895, 8 pages, ; (b) K. Janowska, R. Matczak, J. Zakrzewski and H. Krawczyk, Tetrahedron Lett., 2012, 53, 6504; (c) M. Wrzesiński, D. Mielecki, P. Szczeciński, H. Krawczyk and E. Grzesiuk, Tetrahedron, 2016, 72, 3877; (d) D. Garbicz, D. Mielecki, M. Wrzesiński, T. Pilżys, M. Marcinkowski, J. Piwowarski, J. Dębski, E. Palak, P. Szczeciński, H. Krawczyk and E. Grzesiuk, Curr. Cancer Drug Targets, 2017, DOI: 10.2174/ 1568009617666170623120742.

19 For reviews on Prins cyclization see: $(a)$ E. Arundale and L. A. Mikeska, Chem. Rev., 1952, 51, 505; (b) B. B. Snider in The Prins Reaction and Carbonyl Ene Reactions, ed. B. M. Trost, I. Fleming and C. H. Heathcock, Pergamon Press, New York, 1991, vol. 2, pp. 527-561; (c) S. J. ÁlvarezMéndez, C. García and V. S. Martín, Chem. Commun., 2016, 52, 3380; (d) I. M. Pastor and M. Yus, Curr. Org. Chem., 2012, 16, 1277; (e) C. Olier, M. Kaafarani, S. Gastaldi and M. P. Bertrand, Tetrahedron, 2010, 66, 413For reviews on the use of the Prins cyclization in total synthesis see: $(f)$ U. Biermann, A. Lützen and J. O. Metzger, Eur. J. Org. Chem., 2006, 2631; $(g)$ L. E. Overman and L. D. Pennington, J. Org. Chem., 2003, 68, 7143; (h) I. M. Pastor and M. Yus, Curr. Org. Chem., 2007, 11, 925; (i) E. A. Crane and K. A. Scheidt, Angew. Chem. Int. Ed., 2010, 49, 8316; Angew. Chem., 2010, 122, 8494.

20 For recent reviews, see: (a) R. A. Altman, B. L. Nilsson, L. E. Overman, J. R. Alaniz, J. M. Rohde and V. Taupin, J. Org. Chem., 2010, 75, 7519; (b) B. V. S. Reddy, D. N. Chaya, J. S. Yadav and R. Grée, Synthesis, 2012, 297; (c) V. Durel, C. Lalli, T. Roisnel and P. van de Weghe, J. Org. Chem., 2016, 81, 849; (d) K. Tadpetch and S. D. Rychnovsky, Org. Lett., 2008, 10, 4839; (e) Y. Xie, G.-J. Cheng, S. Lee, P. S. J. Kaib, W. Thiel and B. List, J. Am. Chem. Soc., 2016, 138, 14538; $(f)$ T. Katamura, T. Shimizu, Y. Mutoh and S. Saito, Org. Lett., 2017, 19, 266; $(g)$ B. V. S. Reddy, 
P. N. Nair, A. Antony, C. Lalli and R. Grée, Eur. J. Org. Chem., 2017, 1805.

21 T. Bach and J. Löbel, Synthesis, 2002, 2521.

22 J. S. B. Yadav, V. Subba Reddy, A. V. Hara Gopal, G. G. K. S. Narayana Kumar, C. Madavi and A. C. Kunwar, Tetrahedron Lett., 2008, 49, 4420.
23 (a) K. Han, S. Chen, W. H. Chen, Q. Lei, Y. Liu, R. X. Zhuo and X. Z. Zhang, Biomaterials, 2013, 34, 4680; (b) X. Dai and C. Tan, Adv. Drug Delivery Rev., 2015, 81, 184; (c) Y. Zhao, B. R. Yu, H. Hu, Y. Hu, N. N. Zhao and F. J. Xu, ACS Appl. Mater. Interfaces, 2014, 6, 17911; (d) B. Yang, X. Dong, Q. Lei, R. Zhuo, J. Feng and X. Zhang, ACS Appl. Mater. Interfaces, 2015, 7, 22084. 